\title{
Women's Motivations for Sex: Exploring the Diagnostic and Statistical Manual, Fourth Edition, Text Revision Criteria for Hypoactive Sexual Desire and Female Sexual Arousal Disorders
}

\author{
Ana A. Carvalheira, PhD, ${ }^{*}$ Lori A. Brotto, $\mathrm{PhD},{ }^{\dagger}$ and Isabel Leal, $\mathrm{PhD}^{*}$ \\ ${ }^{*}$ Research Unit of Psychology \& Health, University Institute of Applied Psychology, Lisbon, Portugal; † Department of \\ Obstetrics and Gynaecology, University of British Columbia, Vancouver, Canada
}

DOI: 10.1111/j.1743-6109.2009.01693.x

A B S T R A C T

Introduction. There are problems with the existing definition of hypoactive sexual desire disorder (HSDD) in that desire for sex and sexual fantasy are not a universal experience.

Aims. To explore: (i) women's motivations to engage in sexual activity; (ii) frequency and predictors of sexual fantasies; (iii) sexual arousal; (iv) recognition of sexual arousal; and (v) association between relationship duration and these variables.

Methods. Three thousand six hundred eighty-seven women completed a web-based survey of previously pilot-tested items.

Main Outcome Measures. Investigator-derived self-report questions of sexual desire and arousal, and sexual fantasies. Results. Among women who easily became aroused, $15.5 \%$ reported only engaging in sex if they felt sexual desire at the outset whereas $30.7 \%$ typically or always accessed desire only once they were aroused. Women in longer-term relationships engaged in sex with no sexual desire more often (42\%) than women in short-term relationships (22.4\%) $(P<0.001)$. The percentage of women that reported fantasies only sometimes was $52.5 \%$. A logistic regression revealed that religion (odds ratio $[\mathrm{OR}]=1.45 ; P<0.001$ ), difficulty getting aroused $(\mathrm{OR}=0.511 ; P<0.001$ ), responsive desire $(\mathrm{OR}=0.919 ; P<0.05)$, and frequency of orgasm $(\mathrm{OR}=1.11 ; P<0.05)$ were significantly associated with sexual fantasy. After controlling for age, relationship duration was negatively associated with frequency of initiating $\operatorname{sex}(r=-0.116, P<0.001)$, women's satisfaction with their own sexuality $(r=-0.173, P<0.001)$ and sexual satisfaction with the partner $(r=-0.162, P<0.001)$.

Conclusions. Results reflect diversity in women's motivations for sex, and there is evidence that responsive desire occurs in women with and without arousal difficulties. We strongly recommend relationship duration as well as adequacy of partner sexual stimulation to be recognized in any future diagnostic framework of dysfunction. Clinical implications as well as those for future diagnostic nomenclature are considered. Carvalheira AA, Brotto LA, and Leal I. Women's motivations for sex: Exploring the Diagnostic and Statistical Manual, Fourth Edition, Text Revision criteria for hypoactive sexual desire and female sexual arousal disorders. J Sex Med 2010;7:1454-1463.

Key Words. Sexual Desire; Hypoactive Sexual Desire; Models of Sexual Response; DSM-IV-TR; Classification

\section{Introduction}

The Diagnostic and Statistical Manual, TR) definition of hypoactive sexual desire disorder (HSDD) is based on monosymptomatic criteria. The experience of absent or deficient sexual fantasies and desire for sexual activity is the hallmark feature of HSDD (criterion A) when it is accompanied by marked distress or interpersonal difficulty (criterion B). However, the notion that sexual desire is defined by sexual fantasy frequency and desire for sexual activity has been challenged. For example, research shows that 
many women deliberately evoke fantasies as a means of boosting sexual arousal [1]. Moreover, there are data available to suggest that sexual fantasy frequency is not associated with sexual satisfaction [2]. Qualitative data in mid-aged women find that although women report having experienced a fantasy when directly asked on a selfreport questionnaire, they rarely mention fantasy as being a component of their sexual desire when asked open-ended questions about how their desire is expressed [3].

The second feature of the monosymptomatic criteria for HSDD focuses on the lack of desire for sexual activity. This has been criticized because of the finding that sexual activity often takes place in the absence of sexual desire [4-6], sexual desire does not necessarily lead to sexual activity $[3,7]$, and because despite a low sexual frequency experienced in a large multiethnic sample of perimenopausal women, the majority of the sample remained sexually satisfied [2]. In a series of studies performed by Meston and colleagues, women reported a large number of reasons for engaging in sexual activity or for having sexual desire [8-10]. Reasons associated with "because I was in the mood/horny" were infrequently provided by women, reinforcing the notion that responses to competent stimuli may be what drive women to engage in sex.

These findings have led to the suggestion that women may not require sexual desire at the outset of a sexual interaction in order to engage in sexual activity. Instead, sexual desire may be experienced after sexual arousal, which emerges during a sexual interaction. This type of desire, which emerges in response to arousal, has been termed responsive sexual desire. There is support from qualitative studies that women often experience sexual arousal before sexual desire [3,7]. However, a model of sexual response based on this notion of responsive sexual desire potentially being as important or more important for some women-even for a majority of women-has been criticized for lacking empirical support $[11,12]$. It has also recently been suggested that there may not be one universal sexual response cycle fitting for all women $[11,13]$. Moreover, the extent to which a model of responsive sexual desire is fitting for women only or is also applicable to men has also been examined. Indeed, qualitative research with men supports the proposition that men (like women) can experience sexual desire after arousal [14], and men do not necessarily follow the linear sexual response cycle of: desire then arousal then orgasm.
A third notable feature of the criteria for HSDD is that the clinician is advised to take into account "factors that affect sexual functioning, such as age and the context of a person's life" [15]. Among such contextual variables thought to influence desire for sexual activity is relationship duration. Sexual desire and sexual activity decline in women as the duration of partnership increases [5]; as well, satisfaction with sex decreases [16]. Evidence from nationally representative community samples of adult women confirms the finding of infrequent "spontaneous" sexual thinking (i.e., desire in the absence of stimuli) in the majority of sexually healthy women in longer-term relationships $[1,17,18]$. Clinical observation suggests that women more routinely recall or report internal feelings of desire or desire where there are no obvious external stimuli (so called "spontaneous desire") in terms of sexual thoughts and fantasies in new, as opposed to established relationships [19]. In the sexual response cycle formulated by Basson [20], the absence of sexual desire at the outset of sexual activity may be normative, particularly for women in long-term relationships. The model clarifies flexibility of women's sexual response in that initial awareness of desire may or may not be present. However, support for this model has never been examined in any large-scale empirical study, except in a recent online convenience sample in which it was found that women with and without sexual dysfunction (as measured by scores on a self-report questionnaire) could identify with a circular model of sexual response emphasizing responsive desire [13]. This is in contrast to another convenience sample study of American nurses in which it was found that only women with sexual dysfunction identified with a circular model of sexual response [11].

Whereas the diagnosis of HSDD in women requires that "the judgment of deficiency or absence is made by the clinician, taking into account factors that affect sexual functioning, such as age and the context of the person's life" [15] little guidance is offered in the DSM as to how the clinician might judge contextual factors such as relationship duration. Similarly, the text for female sexual arousal disorder (FSAD) indicates that the diagnosis is not "appropriate if the problems in arousal are caused by sexual stimulation that is not adequate in focus, intensity, and duration" ([15] p. 501); however, how such "adequate stimulation" is to be assessed is not described. How women themselves describe the adequacy of their partner's sexual stimulation has never been studied. 


\section{Aim}

The aim of this study was to explore specific aspects of the DSM-IV-TR criteria for HSDD and FSAD in an online sample of Portuguese women. Specifically we wished to examine: (1) women's motivations to engage in sexual activity (sexual desire at the outset and women's initiative for sexual activity); (2) the frequency and the predictors of sexual fantasies; (3) the expression of sexual arousal (including arousal difficulties and the potential role of adequate partner sexual stimulation); (4) women's recognition of their sexual arousal; and (5) the association between relationship duration and each of these variables.

\section{Methods}

\section{Participants}

\section{Demographic Variables}

A total of 3,687 women completed the questionnaires in full. All were living in Portugal and were of Portuguese nationality. All regions of the country were represented in the sample, although the majority of participants lived in larger metropolitan cities. The average age of participants was 29.4 (standard deviation $=8.3$; range $=17-75$ ) . The online sample was more educated than the national average (See Table 1). Most were in a committed relationship. Data on length of relationship and religion are presented in Table 1.

\section{Reproductive and Health-Related Variables}

A minority of women was pregnant at the time of participation (3.4\%), some women were less than 6 months postpartum (1.5\%), and $1.3 \%$ were breastfeeding. One hundred twenty-two were postmenopausal (3.3\%), and 103 were receiving hormonal therapy $(2.8 \%)$. Sixteen percent of women had received psychological or psychiatric therapy over the last 2 years and $9.8 \%$ were taking antidepressants. A small proportion (9.2\%) reported to have experienced sexual abuse at some point in their lives.

\section{Measures}

A comprehensive, detailed questionnaire was developed for this study. This was necessary as no validated questionnaires were available that assessed responsive sexual desire in Portuguese. The questions were selected on the basis of clinical experience, consultation with international sexual medicine leaders, literature review, and women's narratives on sexual desire and arousal.
Table 1 Demographic variables

\begin{tabular}{|c|c|c|}
\hline & \multicolumn{2}{|c|}{ Women $(\mathrm{N}=3,687)$} \\
\hline & $\%$ & $\mathrm{~N}$ \\
\hline \multicolumn{3}{|l|}{ Education } \\
\hline High school diploma or less & 29.6 & 1,091 \\
\hline University degree & 52.2 & 1,923 \\
\hline Postgraduate degree & 18.3 & 673 \\
\hline \multicolumn{3}{|l|}{ Marital status } \\
\hline Single & 55.6 & 2,051 \\
\hline Married & 23.1 & 851 \\
\hline Common-law & 13.2 & 487 \\
\hline Divorced/separated & 7.5 & 276 \\
\hline Widowed & 0.6 & 22 \\
\hline \multicolumn{3}{|l|}{ Relationship status } \\
\hline In a committed relationship & 77.2 & 2,845 \\
\hline Not committed, sexually active & 11.0 & 406 \\
\hline Not committed, not sexually active & 11.8 & 436 \\
\hline \multicolumn{3}{|l|}{ Length of relationship $(N=2,845)$} \\
\hline$<6$ months & 9.4 & 122 \\
\hline 6 months -1 year & 7.3 & 269 \\
\hline $1-3$ years & 19.6 & 722 \\
\hline $3-5$ years & 12.9 & 475 \\
\hline $5-10$ years & 18.4 & 680 \\
\hline$>10$ years & 15.6 & 577 \\
\hline \multicolumn{3}{|l|}{ Religion } \\
\hline Catholic (practicing) & 12.1 & 445 \\
\hline Catholic (observant) & 52.0 & 1,919 \\
\hline Other religion (practicing) & 2.0 & 73 \\
\hline Other religion (observant) & 2.4 & 87 \\
\hline No religion & 31.5 & 1,163 \\
\hline \multicolumn{3}{|l|}{ Sexual orientation } \\
\hline Heterosexual & 89.2 & 3,287 \\
\hline Homosexual & 4.1 & 151 \\
\hline Bisexual & 5.4 & 198 \\
\hline Undefined & 1.4 & 51 \\
\hline
\end{tabular}

The 59-item questionnaire included: (i) sociodemographic items (age, educational level, marital and relationship status, length of relationship, religion, sexual orientation); (ii) brief mental health history (psychological or psychiatric treatment over the last 2 years, use of antidepressants) and reproductive life cycle (pregnancy, breastfeeding, having a child under the age of 6 months, menopausal status, use of hormonal therapy); (iii) frequency of initiating sexual activity with a partner; (iv) sexual desire and arousal at onset of sexual activity; (v) difficulty with arousal; (vi) orgasmic ease; (vii) experience and signs of recognizing sexual arousal (aspects involved in the awareness of sexual arousal; how women interpret sexual arousal); (viii) frequency of erotic fantasies; and (ix) satisfaction with stimulation received from a partner. All questions had forced-choice response options presented on a 5-point Likert scale.

Although the Female Sexual Function Index (FSFI) [21] has been used in two previous studies in which the relevance of different models of sexual response for women was assessed $[11,13]$, 
the FSFI penalizes women who report little desire at the outset of sex by focusing the two items assessing sexual desire on "a feeling that includes wanting to have a sexual experience." Thus, to identify sexually functional and dysfunctional women for subgroup analyses, we used the criterion from our own developed questionnaire in which the functional group excluded any woman who self-reported difficulty becoming sexually aroused.

\section{Procedure}

A research website and database were created. Complete data from the survey were stored in a database linked to a university server. A username and password were established to ensure database security. Pilot testing was carried out to verify the integrity of the website and establish face validity of the items. We asked women to comment on the clarity of the items, the relevance of the content, and whether any items should be deleted or modified. The purpose of this initial step was to meet basic psychometric criteria, that is, to be clear and understandable and to provide comprehensive response choices. Technical errors were identified and corrected during pilot testing.

Participants were recruited through passive advertisement and snowball by e-mail. The survey was placed on one of the most popular Portuguese websites (http://www.sapo.pt) in a specific section devoted to women. The study was also linked to some Portuguese blogs mainly written and visited by women. The survey was open to recruitment from January to July 2008. After linking to the first webpage that briefly described the study, participants viewed a consent form. Upon agreeing to participate, participants could access the questionnaire. In order to preserve confidentiality, no further information about the respondents was collected or saved. No remuneration was provided. The IP address was used to control multiple submissions and duplicate submissions were deleted.

\section{Statistical Analysis}

We performed nonparametric statistical analyses for ordinal dependent variables. All statistical analyses were performed with SPSS (v. 17.0, SPSS Inc., Chicago, IL, USA). Significant effects were assumed for $P<0.05$. Cases with missing observations were deleted listwise before any analysis was conducted.

We conducted a Mann-Whitney test to compare two independent samples. We conducted a Spearman's correlation coefficient to analyze the relationship between variables. A partial correlation was conducted to explore the influence of relationship duration on some variables of women's sexual response controlling for age. A logistic regression was conducted to examine the predictors of sexual fantasy in this sample. We tested the association between sexual desire at the outset of a sexual encounter and relationship duration with a chi-square test.

\section{Results}

\section{Women's Motivations to Engage in Sexual Activity} Sexual Desire at the Outset of Sexual Activity Our goal was to explore the proportion of both sexually functional and dysfunctional women who engage in sexual activity with no sexual desire at the outset but who become easily sexually aroused after engaging. To identify functional and dysfunctional subgroups, we used the criterion from our own developed questionnaire such that the functional group excluded any woman who reported difficulty becoming sexually aroused. Further inclusion criteria for this subsample (Group 1 -women with no arousal difficulties) were: being heterosexual, having a committed relationship, not taking anti-depressants, not being pregnant or breastfeeding or less than 6 months postpartum, and easily becoming sexually aroused $(\mathrm{N}=1,865)$. Our dysfunctional group (Group 2; $\mathrm{N}=321$ ) included women who met the same inclusion criteria but who self-reported difficulties becoming sexually aroused.

Analysis of sexual response in women in Group 1 showed that $15.5 \%$ only engaged in sexual activity if they felt sexual desire at the outset whereas $30.7 \%$ typically or always accessed desire only once they were aroused (Table 2). Significantly more women with arousal difficulties would engage in sexual activity with no desire at the outset (median $=3$, corresponding to often) compared with women with no arousal difficulties (median $=2$, corresponding to occasionally), $\mathrm{U}=231,201.5, P<0.001$ (Table 2).

We then explored if women in short-term relationships (defined as less than 1 year in duration) report more sexual desire at the outset than women in longer term (defined as more than 10 years relationships). Women in short-term and long-term relationships differed significantly on this variable. The percentage of women engaging in sexual activity with no sexual desire at the outset was higher among those in longer-term relationships. Of the women in longer-term relationships, $42.2 \%$ reported engaging in sexual activity with no 
Table 2 Frequency of engaging in sexual activity with no initial sexual desire among women with $(\mathrm{N}=321)$ and without $(N=1,865)$ sexual arousal difficulties

\begin{tabular}{|c|c|c|c|c|}
\hline \multirow{2}{*}{$\begin{array}{l}\text { How often do you engage } \\
\text { in sexual activity, with no } \\
\text { sexual desire, but after } \\
\text { you begin engaging you } \\
\text { can easily get aroused? }\end{array}$} & \multicolumn{2}{|c|}{$\begin{array}{l}\text { Group } 1 \\
\text { Partnered } \\
\text { women with } \\
\text { no arousal } \\
\text { difficulties }\end{array}$} & \multicolumn{2}{|c|}{$\begin{array}{l}\text { Group } 2 \\
\text { Partnered } \\
\text { women with } \\
\text { arousal } \\
\text { difficulties }\end{array}$} \\
\hline & $\%$ & $\mathrm{~N}$ & $\%$ & $\mathrm{~N}$ \\
\hline Never (1) & 15.5 & 290 & 7.8 & 25 \\
\hline Occasionally (2) & 53.8 & 1,003 & 40.8 & 131 \\
\hline Often (3) & 20.8 & 388 & 34.6 & 111 \\
\hline Very often (4) & 7.7 & 143 & 15.3 & 49 \\
\hline Always (5) & 2.2 & 41 & 1.6 & 5 \\
\hline
\end{tabular}

The numbers in parentheses reflect the 1-5 Likert options presented to participants.

Table 3 Desire for sexual activity and relationship duration

\begin{tabular}{|c|c|c|c|c|}
\hline \multirow{2}{*}{$\begin{array}{l}\text { How often do you engage } \\
\text { in sexual activity, with no } \\
\text { sexual desire, but after } \\
\text { you begin engaging you } \\
\text { can easily get aroused? }\end{array}$} & \multicolumn{2}{|c|}{$\begin{array}{l}\text { Women in } \\
\text { short-term } \\
\text { relationship } \\
<1 \text { year } \\
(\mathrm{N}=616)\end{array}$} & \multicolumn{2}{|c|}{$\begin{array}{l}\text { Women in } \\
\text { long-term } \\
\text { relationship } \\
>10 \text { years } \\
(\mathrm{N}=577)\end{array}$} \\
\hline & $\%$ & $\mathrm{~N}$ & $\%$ & $\mathrm{~N}$ \\
\hline Never (1) & 29.2 & 180 & 8.8 & 51 \\
\hline Occasionally (2) & 48.4 & 298 & 49.0 & 283 \\
\hline Often (3) & 12.5 & 77 & 26.0 & 150 \\
\hline Very often (4) & 6.7 & 41 & 12.7 & 73 \\
\hline Always (5) & 3.2 & 20 & 3.5 & 20 \\
\hline
\end{tabular}

The numbers in parentheses reflect the 1-5 Likert options presented to participants.

desire at the outset from often to always, whereas $22.4 \%$ of those in short-term relationships did so often to always, $\chi^{2}(4)=103.72, \quad P<0.001$ (Table 3).

\section{Initiating/Engaging in Sexual Activity with a Partner}

We explored how often women reported engaging in sexual activity "just because my partner wants to." Among women with a current sexual partner $(\mathrm{N}=3,251), \quad 72.3 \%$ reported initiating sexual activity sometimes. The vast majority of women $(85.3 \%)$ never or only occasionally engaged in sex just to please a partner (Table 4).

Relationship length correlated negatively with the frequency with which women initiated sexual activity with a partner $\left(r_{\mathrm{s}}=-0.136, P<0.01, \mathrm{~N}=\right.$ 2,845 committed women) and positively with women engaging in a sexual interaction to please the partner $\left(r_{\mathrm{s}}=0.208, \quad P<0.01, \quad \mathrm{~N}=2,845\right)$. Longer relationships were associated with women engaging in sexual activity to please a partner, and with a decrease in the frequency of women initiating sexual activity.

\section{Sexual Fantasy}

Only $12 \%$ of the full sample of women reported having sexual fantasies often, and half of the women reported sometimes. Data were very similar in the subsample of women who easily became sexually aroused (Table 5).

A logistic regression was conducted to assess whether religion (Catholic vs. Non-Catholic), age, relationship duration, frequency of orgasm, difficulty getting aroused, responsive desire, and sexual satisfaction with her own sexuality and with a partner could predict sexual fantasy $(\mathrm{N}=3,251$ women with a current sexual partner). The variable sexual fantasy was dichotomized (no = never/ occasionally; yes = sometimes/often). The overall model was found to be significant $\left(\chi^{2}[6]=163.58\right.$, $P<0.001$ ) and revealed that religion (odds ratio $[\mathrm{OR}]=1.45 ; P<0.001)$, arousal $(\mathrm{OR}=0.511 ; P<$ $0.001)$, responsive desire $(\mathrm{OR}=0.919 ; P<0.05)$, and frequency of orgasm $(\mathrm{OR}=1.11 ; P<0.05)$ were significantly associated with sexual fantasy. Non-Catholic women and women who reported a high frequency of orgasm were more likely to report sexual fantasy. In addition, sexual satisfaction with her own sexuality as well as sexual satisfaction with a partner, and length of the relationship did not predict the likelihood of sexual fantasy. Results of the full model are presented in Table 6 . As it became more difficult for

Table 4 Frequency of initiating sex and engaging in sex to please a partner $(\mathrm{N}=3,251)$

\begin{tabular}{lll}
\hline & $\begin{array}{l}\text { How often do } \\
\text { you initiate } \\
\text { sexual activity } \\
\text { with your } \\
\text { partner? (\%) }\end{array}$ & $\begin{array}{l}\text { How often do } \\
\text { you engage in } \\
\text { sexual activity } \\
\text { just because } \\
\text { your partner } \\
\text { wants to? (\%) }\end{array}$ \\
\hline Never & 1.8 & 41.6 \\
Occasionally & 14.3 & 43.7 \\
Sometimes & 72.3 & 8.9 \\
Very often & 10.8 & 4.5 \\
Always & 0.8 & 1.3
\end{tabular}

Table 5 Frequency of sexual fantasy

\begin{tabular}{lll}
\hline $\begin{array}{l}\text { How frequently do } \\
\text { you have sexual } \\
\text { fantasies? }\end{array}$ & $\begin{array}{l}\text { Total sample } \\
(\mathrm{N}=3,687) \%\end{array}$ & $\begin{array}{l}\text { Women who } \\
\text { easily become } \\
\text { sexually aroused* } \\
(\mathrm{N}=2,423) \%\end{array}$ \\
\hline Never & 7.3 & 5.8 \\
Occasionally & 28.2 & 27.2 \\
Sometimes & 52.5 & 54.2 \\
Often & 12.0 & 12.8 \\
\hline
\end{tabular}

${ }^{*}$ Not taking antidepressants, not pregnant, or breastfeeding. 
Table 6 Predictors of sexual fantasy $(N=3,251)$

\begin{tabular}{llrc}
\hline Variable & $\begin{array}{l}\text { Odds } \\
\text { ratio }\end{array}$ & \multicolumn{1}{c}{$P$} & \multicolumn{1}{c}{$B$} \\
\hline Age & 1.00 & 0.769 & - \\
Religion (Catholic/non-Catholic) & 1.45 & $<0.001$ & 0.371 \\
Relationship duration & 0.980 & 0.475 & - \\
Frequency of orgasm & 1.11 & 0.006 & 0.112 \\
Difficulty getting aroused & 0.511 & $<0.001$ & -0.672 \\
Sexual satisfaction with own & 0.951 & 0.555 & - \\
$\quad$ sexuality & & & - \\
Sexual satisfaction with partner & 0.990 & 0.897 & - \\
Responsive desire* & 0.919 & 0.049 & -0.085
\end{tabular}

${ }^{*}$ Responsive desire was measured with the item "How often do you engage in sexual activity with no sexual desire, but after you begin engaging you can easily get aroused?". The variable "sexual fantasy" was dichotomized (no = never/occasionally; yes = sometimes/often).

women to get sexually aroused, the likelihood of having sexual fantasies decreased.

\section{Women's Experience of Sexual Arousal}

A subsample of 3,251 partnered women responded to the question "How difficult is it for you to get sexually aroused in your sexual relationship?": $19.5 \%$ reported very easy, $66.7 \%$ moderately easy, $12.4 \%$ moderately difficult, and $1.4 \%$ very difficult. Nevertheless, $56 \%$ of partnered women who easily became sexually aroused $(\mathrm{N}=2,803)$ reported they would like to receive more and/or better physical stimulation from their partner in order to get sexually aroused. Also interesting among this subgroup was the finding that $74.3 \%$ reported that they had no desire at the outset of the sexual encounter but were able to experience desire after becoming aroused. Among women who found it difficult to get sexually aroused, $72.1 \%$ reported they would like to receive more and/or better physical stimulation from a partner.

There was no significant correlation between ease of arousal and age, educational level, and religion, all $P \mathrm{~s}>0.05$.

There was a negative correlation between difficulty getting sexually aroused and a woman's satisfaction with her own sexuality $\left(r_{\mathrm{s}}=-0.33\right.$, $P<0.001)$ and sexual satisfaction with the partner $\left(r_{\mathrm{s}}=-0.32, P<0.001 ; \mathrm{N}=2,845\right.$ women in committed relationship). The more difficult it was for women to get sexually aroused, the less satisfied they were with their own sexuality and with their partners.

\section{Women's Recognition of Sexual Arousal}

In order to identify aspects involved in the awareness of sexual arousal, we presented seven different response categories from which women could choose. Analyses were performed on a subsample of heterosexual women in a committed relationship, not taking anti-depressants, not pregnant or breastfeeding, and not less than 6 months postpartum $(\mathrm{N}=1,865)$. In response to the question "How do you become conscious that you are getting sexually aroused?", the vast majority of women reported "Because I feel like having sex." Less than half of women reported physical genital sensations that were presented on three response categories: vaginal wetness (46.3\%); sensations of warmth in the vagina $(24.5 \%)$; and physical sensations in the vagina $(40.6 \%)$ (Table 7 ).

\section{Influence of Relationship Duration}

A partial correlation revealed some significant associations between relationship duration and other variables after controlling for age. There was a significant negative correlation between length of relationship and the frequency with which women initiated a sexual interaction with their partner $(r=-0.116, P<0.001)$. There was also a significant negative correlation between length of the relationship and women's satisfaction with their own sexuality $(r=-0.173, P<0.001)$ and sexual satisfaction with the partner $(r=-0.162, P<0.001)$. There was a significant positive correlation between the length of relationship and engaging in a sexual interaction to please the partner $(r=0.131$, $P<0.001)$, and difficulty achieving sexual arousal $(r=0.149, P<0.001)$. We also found a very small but significant negative correlation between the duration of the relationship and frequency of erotic fantasies $(r=-0.061, P<0.001)$.

\section{Discussion}

The experience of absent or deficient sexual fantasies and desire for sexual activity is the hallmark feature of HSDD when it is accompanied by

Table 7 Correlates of sexual arousal among partnered women with no sexual arousal difficulties $(N=1,865)$

\begin{tabular}{ll}
\hline How do you know when you are & $\begin{array}{l}\text { Partnered women } \\
\text { with no arousal } \\
\text { difficulties* \% }\end{array}$ \\
\hline I feel like having sex & 80.2 \\
My vagina feels wet & 46.3 \\
I have physical sensations in my vagina & 40.6 \\
I have a subjective feeling of pleasure & 29.4 \\
I feel a kind of heat in my vagina & 24.5 \\
I feel like masturbating & 17.7 \\
\hline
\end{tabular}

*Heterosexual women in a committed relationship, not taking antidepressants, not pregnant or breastfeeding, not less than 6 months postpartum. 
marked distress or interpersonal difficulty. The present study provides some results that challenge this narrow conceptualization of desire.

\section{The Experience of Sexual Fantasy}

Results did not reveal a high frequency of sexual fantasy in this sample. Half of the women reported having sexual fantasies sometimes and one-third reported rarely or never. Only 12\% reported having sexual fantasies often. This proportion did not differ significantly for women who easily became sexually aroused. These data legitimately question the universality of fantasy as denoting satisfying sexual response and being a sign of desire. Fantasy may be important for some women but not for others, highlighting the complexity and individual variability in the female sexual response. The findings also replicate the findings of others that show that women do not mention fantasies in their narrative descriptions of desire [3], and that women may deliberately use fantasy as a means of boosting sexual arousal $[4,22]$. On the other hand, sexual satisfaction with their own sexuality as well as sexual satisfaction with a partner did not predict sexual fantasy, replicating prior research [23].

\section{The Desire for Sexual Activity}

Our data revealed that "to please a partner" may be one of many reasons why women engage in sexual activity. Furthermore, women can engage in sexual activity, with or without sexual desire at the outset, but after engaging sexually, they were able to easily become sexually aroused.

Our goal was to explore-in a sample of sexually healthy women - the proportion who engaged in sexual activity with no sexual desire at the outset but who become easily sexually aroused after engaging. Among those women who reported no arousal difficulties with a partner (heterosexual women in a committed relationship, not taking antidepressants, not pregnant or breastfeeding, and not less than 6 months postpartum; $\mathrm{N}=$ $1,865)$, women who engaged in sexual activity only when they felt sexual desire represented a small group $(15.5 \%)$. On the other hand, there was a much larger group of women who engaged occasionally with no sexual desire $(53.8 \%)$ at that moment but then experienced arousal during the subsequent sexual activity, and another group of women who engaged with no desire most of the time $(30.7 \%)$, but again eventually experienced arousal and desire during the interaction. Women in the latter two groups would be described as experiencing responsive desire-i.e., experiencing desire after sexual arousal. These data reflect diversity in women's sexual response regarding motivation to engage sexually and suggest that some women experience desire and arousal as overlapping entities taking place in a variable order. This also supports qualitative findings of a high degree of overlap between desire and arousal [3,7]. Furthermore, these results show that sexual desire may or may not be present at the outset of a sexual interaction. According to these data, not every sexual encounter occurs as a consequence of experienced sexual desire. Moreover, the overlap between arousal and desire was recently highlighted in a critical review of the DSM-IV-TR diagnostic criteria for FSAD [24].

\section{Sexual Desire and Arousal}

The majority of women $(80.2 \%)$ reported recognizing arousal when they felt motivated to have sex. To become sexually aroused and to be motivated to have sex had equivalent meanings for the majority of women. Consistent with previous studies, these data support the observation that women may not separate "sexual desire" from "arousal" [3,7,21,25-27]. These data refute the concept that desire and arousal are discrete entities and support the future conceptualization of a desire-arousal entity. Additionally, findings from a recent study with a sample of 427 surgically menopausal women in European countries showed a strong positive correlation between sexual desire and arousal $(P<0.001)[28]$.

We also aimed to analyze the importance of genital changes in women's experience of arousal. Genital sensations were identified as markers of sexual arousal by less than half of women, calling into question the focus on deficient lubrication and swelling response of sexual excitement that form the basis of FSAD in the DSM-IV-TR. According to our results, women's lack of recognition that perceived genital sensations are strong indicators of overall sexual arousal challenges the usefulness of genital lubrication as the hallmark definition of sexual arousal. These data are also supported by a large body of research showing lower concordance between genital response and subjective reports of arousal in women [29-35]. In recognition of the problematic nature of the DSM-IV-TR definition of FSAD, modifications to the criteria and expansion of the definition have already been proposed $[17,36]$. It is clear that many women do not assess their experience of arousal on the basis of genital sensations. Subjective arousal is influenced by thoughts and emotions [37,38]. Considering the 
complexity of female sexual arousal, the separation of genital and subjective subtypes of arousal disorders can be very useful to clinical assessment and management of women's complaints.

\section{Contextual Factors that Affect Female Sexual Functioning}

The DSM-IV-TR definition of HSDD requires that the clinician take into account "factors that affect sexual functioning, such as age and the context of a person's life" [15]. Among such contextual variables thought to influence desire for sexual activity, the present study addressed relationship duration and effectiveness of partner stimulation. Among women who found it difficult to get sexually aroused, the majority reported they would have liked to receive more effective physical stimulation from a sexual partner. Importantly, even in the subsample of partnered women who easily became sexually aroused, $56 \%$ reported the same wish. It is possible, therefore, that in the vast majority of cases in which a clinician would administer a diagnosis of FSAD, that if more effective stimulation were applied, arousal may not be impaired, and the FSAD diagnosis would not be given. These data reinforce that adequate and sufficient sexual stimulation is required and very important to women's sexual experience. More importantly, diagnosing a sexual dysfunction in a woman when the etiology is related to poor technique or (perhaps) partner-dependent factors seems illogical. Although at present a method for grading degree of adequacy of stimulation is not built into the diagnostic system, sufficiency of partner sexual stimulation must be considered in any future diagnostic framework of sexual dysfunction, given that inadequate stimulation may, in some cases, be ostensibly responsible for the apparent "dysfunction". Basson's model of female sexual response has highlighted the importance of sufficient and adequate stimuli modulating the female response cycle $[12,19]$.

Relationship duration is another contextual variable routinely assessed in the clinical situation, but is not included in the diagnostic framework for diagnosing sexual dysfunction. The DSM diagnostic system for sexual dysfunctions instead assumes that sexual dysfunctions are situated in the individual. To any clinician with sex or couple therapy expertise, this notion is completely absurd. Our data revealed a negative correlation between relationship duration and some measured aspects of women's sexual response. These results provide further evidence that the proportion of women engaging in sexual activity with no sexual desire increases with relationship duration. There was a decrease in women's initiating sexual activity with increasing relationship duration. Moreover, longer relationships were more commonly associated with women engaging in sexual activity to please the partner. Women's sexual satisfaction with their own sexuality declined as the duration of relationship increased. Sexual satisfaction with the partner also decreased as the duration of relationship increased. Thus, longer relationships were associated with engaging in sexual activity with no sexual desire at the outset, engaging in sexual activity to please the partner, a decline in initiating sexual activity, and decreased sexual satisfaction, which is supported by prior research $[5,16,39,40]$.

This study provides some empirical support for Basson's circular model of female sexual response $[12,19,20]$. Namely, (i) sexual desire precedes sexual arousal only in some women, and it tends to be among women in shorter term relationships; (ii) a majority of women do at least occasionally access desire only after arousal; (iii) a sizable minority (30.7\%) typically or always access desire only once they are aroused; (iv) responsive desire is present in sexually healthy women, and not only among women with sexual dysfunction (countering the conclusions drawn by others [11]); and (v) relationship duration negatively affects women's awareness of untriggered sexual desire: women in longer-term relationships often begin a sexual interaction, not with sexual desire, but from a position of sexual neutrality, motivated by other reasons such as those already previously described [10]. By conceptualizing a cycle that can function with only responsive desire, or alternatively be reinforced at any stage by a degree of initial desire $[12,19]$ the variability and flexibility of women's sexual response is demonstrated.

Clinicians should be aware of the diversity of women's sexual response. Different pathways are possible in the pursuit of pleasure and satisfaction. Distressing lack of spontaneous desire is not a disorder, per se. A comprehensive assessment of women's sexual functioning related to desire and arousal should include a number of contextual variables. Relationship duration must be recognized (short term/longer term), as well as sufficiency and adequacy of partner sexual stimulation. Moreover, an approach that combines desire and arousal into one disorder with polythetic criteria was recently recommended $[24,36]$.

There are limitations in this study that must be considered. The sample is not representative of all 
Portuguese women as the use of an Internet survey preselected more highly educated women. On the other hand, the use of Internet-based research methodology to carry out a survey on such a private topic as sexuality can offer anonymity and privacy to respondents. The reliability and validity of the investigator-derived questionnaire is unknown as it was not validated before use. Although significant, it is important to note that correlations with relationship length are small in most cases. This suggests that the influence of relationship duration on measures of sexual functioning is relatively small and highlights that these variables are likely influenced by a multitude of other variables as well.

Corresponding Author: Ana Carvalheira, PhD, Superior Institute of Applied Psychology, R. Jardim do Tabaco, 34 Lisbon 1149-041, Portugal. Tel: (351) 919-253-757; Fax: (351) 218-860-954; E-mail: ana. carvalheira@ispa.pt, lori.brotto@vch.ca

Conflict of Interest: None.

\section{Statement of Authorship}

Category 1

(a) Conception and Design

Ana A. Carvalheira; Isabel Leal

(b) Acquisition of Data

Ana A. Carvalheira; Isabel Leal

(c) Analysis and Interpretation of Data

Ana A. Carvalheira; Lori A. Brotto

\section{Category 2}

(a) Drafting the Article

Ana A. Carvalheira; Lori A. Brotto

(b) Revising It for Intellectual Content

Ana A. Carvalheira; Lori A. Brotto

\section{Category 3}

(a) Final Approval of the Completed Article

Ana A. Carvalheira; Lori A. Brotto; Isabel Leal

\section{References}

1 Garde K, Lunde I. Female sexual behaviour: The study in a random sample of a 40-year-old women. Maturitas 1980;2: $225-40$.

2 Cain VS, Johannes CB, Avis NE, Mohr B, Schocken M, Skurnick J, Ory $M$. Sexual functioning and practices in a multiethnic study of midlife women: Baseline results from SWAN. J Sex Res 2003;40:266-76.

3 Brotto LA, Heiman JR, Tolman DL. Narratives of desire in mid-age women with and without arousal difficulties. J Sex Res 2009;46:387-98.

4 Hill CA, Preston LK. Individual differences in the experience of sexual motivation: Theory and measurement of dispositional sexual motives. J Sex Res 1996;33:27-45.
5 Klusmann D. Sexual motivation and the duration of partnership. Arch Sex Behav 2002;31:275-87.

6 Regan P, Berscheid E. Belief about the states, goals and objects of sexual desire. Sex Marital Ther 1996;22:110-20.

7 Graham CA, Sanders SA, Milhausen RR, McBride KR. Turning on and turning off: A focus group study of the factors that affect women's sexual arousal. Arch Sex Behav 2004;33: 527-38.

8 McCall K, Meston C. Cues resulting in desire for sexual activity in women. J Sex Med 2006;3:838-52.

9 McCall K, Meston C. Differences between pre- and postmenopausal women in cues for sexual desire. J Sex Med 2007;4:364-71

10 Meston CM, Buss DM. Why humans have sex. Arch Sex Behav 2007;36:477-507.

11 Sand M, Fisher WA. Women's endorsement of models of female sexual response: The nurses' sexuality study. J Sex Med 2007;4:708-19.

12 Basson R. Using a different model for female sexual response to address women's problematic low sexual desire. J Sex Marital Ther 2001;27:395-403.

13 Giles KR, McCabe MP. Conceptualizing women's sexual function: Linear vs. circular models of sexual response. J Sex Med 2009;6:2761-71.

14 Janssen E, McBride KR, Yarber W, Hill BJ, Butler SM. Factors that influence sexual arousal in men: A focus group study. Arch Sex Behav 2008;37:252-65.

15 American Psychiatric Association. Diagnostic and statistical manual of mental disorders. 4th edition. Text revision. Washington, DC: American Psychiatric Association; 2000.

16 Liu C. Does quality of marital sex decline with duration? Arch Sex Behav 2003;32:55-60.

17 Bancroft J, Loftus J, Long JS. Distress about sex: A national survey of women in heterosexual relationships. Arch Sex Behav 2003;32:193-204.

18 Cawood HH, Bancroft J. Steroid hormones, menopause, sexually and well being of women. Psychophysiol Med 1996;26: 925-36.

19 Basson R, Leiblum S, Brotto L, Derogatis L, Fourcroy J, Fugl-Meyer K, Graziottin A, Heiman JR, Laan E, Meston C, Schover L, van Lankveld J, Schultz WW. Definitions of women's sexual dysfunction reconsidered: Advocating expansion and revision. J Psychosom Obstet Gynaecol 2003;24: 221-9.

20 Basson R. The female sexual response: A different model. J Sex Marital Ther 2000;26:51-65.

21 Rosen R, Brown C, Heiman J, Leiblum S, Meston C, Shabsigh D, Ferguson D, D'Agostino R Jr. The Female Sexual Function Index (FSFI): A multidimensional self-report instrument for the assessment of female sexual function. J Sex Marital Ther 2000;26:191-208.

22 Lunde I, Larsen GK, Fog E, Garde K. Sexual desire, orgasm, and sexual fantasies: A study of 625 Danish women born in 1910, 1936, and 1958. J Sex Educ Ther 1991;17:1115 .

23 Davidson JK, Hoffman LE. Sexual fantasies and sexual satisfaction: An empirical analysis of erotic thought. J Sex Res 1986;22:184-205.

24 Graham CA. The DSM Diagnostic criteria for female sexual arousal disorder. Arch Sex Behav 2009; Sep 24 [Epub ahead of print] doi: 10.1007/s10508-009-9535-1.

25 Beck JG, Bozman AW, Qualtrough T. The experience of sexual desire: Psychological correlates in a college sample. J Sex Res 1991;28:443-56.

26 Ellison C. Women's sexualities. Oakland, CA: New Harbinger; 2000.

27 The Working Group for a New View of Women's Sexual Problems. A new view of women's sexual problems. In: 
Kaschak E, Tiefer L, eds. A new view of women's sexual problems. New York: Haworth Press; 2001:1-8.

28 Graziottin A, Koochaki PE, Rodenberg CA, Dennerstein L. The prevalence of hypoactive sexual desire disorder in surgically menopausal women: An epidemiological study of women in four European countries. J Sex Med 2009;6:2143-53.

29 Brotto LA, Gorzalka BB. Genital and subjective sexual arousal in postmenopausal women: Influence of laboratory induced hyperventilation. J Sex Marital Ther 2002;283:39-53.

30 Everaerd W, Laan E, Both S, Van der Velde J. Female sexuality. In: Szuchman L, Muscarella F, eds. Psychological perspectives on human sexuality. New York: Wiley; 2000:108-22.

31 Laan E, Everaerd W, van der Velde J, Geer JH. Determinants of subjective experience of sexual arousal in women: Feedback from genital arousal and erotic stimulus content. Psychophysiology 1995;32:444-51.

32 Laan E, van Driel E, van Lunsen RHW. Seksuele reakties van vrouwen met een seksuele opwindingsstoornis op visuele seksuele stimuli [Sexual responses of women with sexual arousal disorder to visual sexual stimuli]. Tijdschrift Voor Seksuologie 2003;27:1-13.

33 Meston CM, Gorzalka BB. The effects of immediate, delayed and residual sympathetic activation on physiological and subjective sexual arousal in women. Behav Res Ther 1996;34: $143-8$.
34 Meston CM, Heiman JR. Ephedrine-activated physiological sexual arousal in women. Arch Gen Psychiatry 1998;55:652-6, 33.

35 Morokoff PJ, Heiman JR. Effects of erotic stimuli on sexually functional and dysfunctional women: Multiple measures before and after sex therapy. Behav Res Ther 1980;18:127-37.

36 Brotto LA. The DSM diagnostic criteria for hypoactive desire disorder in women. Arch Sex Behav 2009;DOI 10.1007/ s10508-009-9543-1.

37 Nobre PJ, Pinto-Gouveia J. Emotions during sexual activity: Differences between sexually functional and dysfunctional men and women. Arch Sex Behav 2006;35:8-15.

38 Nobre PJ, Pinto-Gouveia J. Cognitions, emotions and sexual response: Analysis of the interaction between automatic thoughts and emotional responses during sexual activity and its impact on sexual arousal. Arch Sex Behav 2008;37:652-61.

39 Hayes RD, Dennerstein L, Bennett CM, Sidat M, Gurrin LC, Fairley CK. Risk factors for female sexual dysfunction in the general population: Exploring factors associated with low sexual function and sexual distress. J Sex Med 2008;5:168193.

40 Rosen RC, Shifren JL, Monz BU, Odom DM, Russo PA, Johannes CB. Correlates of sexually related personal distress in women with low sexual desire. J Sex Med 2009;6:154960 . 